THE APPROACHING ELECTION OF COUNCLLLORS. To the Editor of The LANCET.

Sir,-I I an unwilling to allow this last opportunity of addressing a few more words of caution to the Fellows, upon the necessity of their acting in unison on Wednesday, the 30th inst.; of which they stand much in need, if we may judge from the apathy and neglect they have exhibited at the very opening of the contest. I much regret to see, by the letter which the Council have issued to the Fellows, that Mr. Gosset is the only one, of those rejected or passed over last year, who has sent in the required notice, signed by more than six Fellows, of his intention to offer himself again as a candidate for the racant seat at the Council Board. What can the friends of Mr. Carpue, of Sir Stephen Hammick, of Mr. Macilwain, of Mr. Lloyd, and of Mr. Kingdon, have been about thus, by their neglect, to risk the chance of their beirig excluded from the Council for ever? - for such must now inevitably be the case, should Mr. Gosset be not elected. This has evidently been the game of the Council, which the apathy of the Fellows has allowed them to play only too successfully. They will now have only to defeat Mr. Gosset, and thereby they will save themselves the trouble of any further contest with respect to the other gentlemen. It becomes, then, doubly important to secure the election of Mr. Gosset.

I cannot help thanking both of your correspondents, " $\mathrm{MA}_{\mathrm{A}}$ CHAON," and "A FeLLow," for seconding my humble efforts to expose the intrigues of the Council. 'The latter has sketched an admirable exposition of the moral, social, and legislative qualities of some few of them. But he has omitted their professional distinctions, some few of which, as a pendant to his portraiture, it may not be amiss to subjoin. I likewise will begin with the letters of the alphabet:- $A$ is most assiduous in the study of his profession; he is weekly ground up in his anatomy. Some, it is true, uncharitably say, that, being utterly ignorant of the elements of his profession, he is obliged to undergo that operation to render him fit to examine. B is equally ignorant of minute anatomy, but, unlike his pains-taking colleague, trusts to his repute as a scientific man to cover his deficiencies. Verily, these gentlemen are eminently qualified to be members of an examining body. $\mathbf{B}$, however, has perhaps forgotten what $\mathbf{C}$ never knew, as for knowledge of any kind, save that of the world and the weaknesses of human nature, $C$ never had any. $G$ is particularly skilful in tying the subclavian artery, never having mistaken one of the brachial nerves for the same! I exhibits remarkable acuteness in detecting healthy from diseased intestine in the operation for hernia. $K$ shows the greatest possible care in his operations, and rarely forces lithotrity instruments into the abdomen! $\mathbf{M}$ is remarkably honest with regard to the inventions or discoveries of brother medical men; he is " too uxurious and indolent for anything of the kind," his friends would say, but still he has a strong affection for gilt-wire sutures! But I forbear for the present, in the hope that these little facts will somewhat abridge the freedom with which they eriticise the professional acquirements of others, thus positively inviting inquiry into their own.

July 21 st, 1815.

I am, Sir, your obedient servant, Detur Dignyori.

THE APPROACHING ELECTION OF COUNCIILORS. To the Editor of 'THE LANCET.

SIR,-My views are in unison with those of "A Fellow," who addressed you last week, and I consider that we shall be fully justified in acting, nay, more, that it will be our duty to act, upon the principle which he advocates, by endeavouring to break down the wall of exclusiveness, built up between the great body of the fellows and the council-chamber of the College of Surgeons.

I shall make a point of leaving this place to be present at the College, on the 30th instant, and to Mr. Gosset, and the other mon-hospital surgeons who may come forward, will cordially give my support, in preference to, and to the exclusion of, those connected with hospitals. If anything were wanting to urge me to this course, the straightforward letter from Mr. Gosset, which yon published last year, (contrasting so strongly with the illiberal conduct of the Council towards him,) would be a sufficient inducement.

Do you not, Sir, agree with me, that the remembrance of the unfair treatment (unexplained, unpalliated, undenied) which he met with at their hands, should summon up the honourable feelings of those fellows who are inimical to injustice and (I may add) deceit, and stimulate their exertions to secure his election, even though they may not adopt the extreme views that influence myself, as to the non-election (for a time) of any hospital-surgeons? I am, Sir, your obedient servant,

Cineltenham, July 22nd, 1845 .

ANotier FeLLOW.

\section{EXTENDER FOR REDUCING DISLOCATIONS.} T'o the Editor of The Lancet.

Srr,- - In the reduction of dislocations, it has appeared to me that the usual means-and among these the pulley may be placed-do not effectively afford the condition necessary to the realization of the object in view-namely, a steadily continued and a gradually increased extension.*

The extending force, when made through the medium of towels, sheets, table-cloths, or any similar means, depends wholly on the power of the person or persons who extend, and, in such a case, can be in very few instances applied with a steadily continued and gradually increased force. The want of firmness, sometimes, sometimes the want of power, sympathy with the sufferer at other times, and, indeed, a variety of causes, may tend to make the individuals to extend unsteadily.

The pulley, especially the multiplied pulley, meets in part these dificulties, but only in part, and like the modes above mentioned, requires much muscular exertion on the part of the operator.

In the case of the pulley, the assistant must not only extend steadily, but when the due extension is gained, must, while the surgeon is effecting the coaptation, hold steadily, not giving way in the least, till the joint is positioned. In many cases the assistant does give way a little, and thus loses the object, and the extension has to be made again.

With the view of meeting these difficulties, I have invented an instrument consisting of a torthed bar, moved by a cog-wheel, through which a pinion passes, to which pinion the handle is attached.

This instrument will enable the surgeon to gain the following advantages:-

1st. A steadily continued and gradually increased extension. The steadily continued extension is realized by the extending power being carried on by turning the handle, and thereby drawing in, with mechanical precision, the bar, by which the extension is made. The power can be regulated to the eighth of an inch, the rack preventing the bar from returning. (I had proposed the usual rack applied to $\operatorname{cog}$-wheels, and am indehted to Mr. Coxeter, instrument-maker to University College Hospital, for the present more convenient contrivance.)

2nd. The muscular power necessary to be exercised by the operator, is next almost to nothing; anyone can, by means of this instrument, pull with ease three powerful men. The surgeon has thus not to exhaust his power, and appears as a surgeon, and not as a mere mechanic toiling.

3rd. If can, in addition, by means of the rack, fix the extender at the point he chooses, and then, without any difficulty, can perform the other part of his duty,--namely, the coaptation of the limb to the joint from which it was dislocated; in fact, the extension can be made with one hand, the coaptation with the other.

4 th. This instrument does not require any distance from the patient in order to gain the resistance-the bed-post would do.

Trusting that these advantages will render the extender useful to the profession, and tend to diminish the amount of human suffering, I beg, through the pages of your journal, to offer it to the profession as the contribution of your obedient servant,

University College, London, 1845. George N. Epps.

\section{THE LONDON MEDICAL DIRECTORY. To the Editor of Tue LANCET.}

SIR,-The observations of your correspondent on the "Qualifications of existing Practitioners," at page 54 of THE LA "NCET, for July 12 , and his strictures on the remarks of Dr. Pettigrew, in reference to the "London Medical Directory," appear to demand an explanation. The legally-qualified practitioner, whose qualification was not inserted in the "Directory," would fain have the work considered as no authority at all in consequence thereof. But probably this gentleman has himself to thank for the omission. Was he not inundated with circulars, (all prepaid, directed from the "Red Book,") to obtain from him information as to his qualification to practise?

But to the facts. At random, Dr. Pettigrew opened the book, at page 118, whereon are imprinted nine names, four of which have no qualification to practise annexed. It is remarked in the preface, that "Where names are given, and no qualification is attached, it is to be understood that the parties have made no return, and that the editors have failed to discover their names in the lists of the Colleges of Physicians and Surgeons, or in the Apothecaries' Company. Those who, notwithstanding, are in

* Mr. Samuel Cooper's First Lines, f. 244. Seventh Edition. 1840. 